\title{
RADON ELIMINATION DURING BENZENE PREPARATION FOR RADIOCARBON DATING BY LIQUID SCINTILLATION SPECTROMETRY
}

\author{
DARDEN HOOD, RONALD HATFIELD, \\ CHRISTOPHER PATRICK, JERRY STIPP, MURRY TAMERS \\ Beta Analytic Inc, Coral Gables, Florida 33124
}

\author{
ROBERT LEIDL, BARBARA LYONS, HENRY POLACH, \\ STEVE ROBERTSON and WEIJIAN ZHOU* \\ Radiocarbon Dating Research, Australian National University \\ Canberra 2601, Australia
}

\begin{abstract}
Radon gas is a serious contaminant in radiocarbon dating by radiometry. The low specific ionizations associated with the $\alpha$-particle emitting radon and its $\beta$-particle emitting daughters overlap within the ${ }^{14} \mathrm{C}$ counting window. Elimination of radon is therefore imperative for precise ${ }^{14} \mathrm{C}$ age determinations. This paper deals with the sources and mechanism of incorporation of radon affecting ${ }^{14} \mathrm{C}$ dating by liquid scintillation (LS) counting, and reviews conventional radon elimination practices in ${ }^{14} \mathrm{C}$ laboratories. It demonstrates, based on rigorous multichannel and multiparameter $\alpha$ - and $\beta$-particle spectral analyses of some 1000 benzene samples, that parent radium is not present and that its daughter radon is quantitatively eliminated during dynamic vacuum recovery of benzene at $-78^{\circ} \mathrm{C}$. However, the radon-free benzene can be recontaminated by exposure to air containing traces of radon, such as is common in concrete or low-lying laboratories. The use of radon-free air, when exposing the benzene to the atmosphere, and the monitoring of radon counts from the environment and sample benzene in a fixed 'radon window', are essential prerequisites to the quality control of ${ }^{14} \mathrm{C}$ age determinations in very low background systems.
\end{abstract}

\section{INTRODUCTION}

\section{Sources and Mechanism of Incorporation of Radon}

The high natural abundance of uranium $\left({ }^{238} U\right)$ in the earth's crust ensures the continued presence of its radioactive decay daughters, thorium $\left({ }^{234} \mathrm{Th}\right)$, uranium $\left({ }^{234} \mathrm{U}\right),{ }^{230} \mathrm{Th}$, and radium $\left({ }^{226} \mathrm{Ra}\right) .{ }^{222} \mathrm{Rn}$ is the result of $\alpha$ recoil on decay of its parent ${ }^{226} \mathrm{Ra}$. Incorporation of ${ }^{226} \mathrm{Ra}$ and ${ }^{222} \mathrm{Rn}$ in the sample, during its storage in the archives of nature, ensures that almost all are variably contaminated by ${ }^{222} \mathrm{Rn}$ when submitted for ${ }^{14} \mathrm{C}$ dating. Thus, the mechanism of ${ }^{222} \mathrm{Rn}$ incorporation is two-fold. The primary source will be ${ }^{222} \mathrm{Rn}$ dissolved in groundwaters as these dissolve inert gases when they equilibrate with soil air in amounts proportional to their solubilities and partial pressures. ${ }^{222} \mathrm{Rn}$ content are thus considerably in excess of the ${ }^{226} \mathrm{Ra}$ contents, as is generally observed in groundwaters (Andrews \& Lee, 1979). A lesser source will be the incorporation of ${ }^{226} \mathrm{Ra}$ as its solubilities are gen-

\footnotetext{
*Visiting Fellow (1988) at the ANU Radiocarbon Lab. Permanent address: Xian Laboratory of Loess and Quaternary Geology, Academia Sinica, Xian, China
} 
erally less. ${ }^{222} \mathrm{Rn}$ and ${ }^{226} \mathrm{Ra}$ may thus be present in disproportionate amounts in the sample immediately after collection. Equilibration takes place only after 25 days (Andrews \& Lee, 1979). It follows that samples which did not incorporate ${ }^{226} \mathrm{Ra}$ will not contain measurable traces of ${ }^{222} \mathrm{Rn}$ after that period. On the other hand, all samples incorporating ${ }^{226} \mathrm{Ra}$ will be forever contaminated with ${ }^{222} \mathrm{Rn}$, from the ${ }^{14} \mathrm{C}$ dating practical point of view ${ }^{226} \mathrm{Ra}$ half-life is $1600 \mathrm{yr}$ ).

To adversely affect ${ }^{14} \mathrm{C}$ determinations by radiometry, ${ }^{222} \mathrm{Rn}$ does not have to be incorporated in the sample prior to its submission for dating. The atmosphere within laboratories may contain radon in varying amounts where the buildings are made of concrete or clay bricks containing some uranium, the buildings are sited low in the contours of the landscape with uranium-rich soils, or counting rooms are located in basements where the radon, 10 times heavier than air, will naturally accumulate. Thus, surface active samples such as charcoal, even if originally radon-free, will adsorb radon during exposure to the laboratory atmosphere and become contaminated during handling.

Another effect is that buildup of radon in a low-level counting room will cause an increase in background count rates. As this buildup is seldom constant, a variable background count will result and affect the precision of age determinations (Freundlich, 1972). Further, reagents used in the conversion of sample carbon to benzene, particularly the synthesis catalyst which uses a clay mineral base, and gases $\left(\mathrm{O}_{2}, \mathrm{~N}_{2}, \mathrm{CO}_{2}\right)$ stored in steel cylinders, may incorporate uranium series decay products, and hence be contaminated with radon. Samples prepared for LS spectrometry can thus be contaminated during any stage of the benzene synthesis.

Last, when a sample of radon-free benzene has been prepared, it is important to equilibrate it with air to avoid variable quench from dissolved $\mathrm{O}_{2}$ content. If the laboratory air contains radon, the benzene sample will become contaminated during $\mathrm{O}_{2}$ equilibration process.

\section{Radon Elimination}

Radon elimination from the gas phase is based either on slow fractional distillation at controlled temperatures (de Vries, 1957), the more generally accepted chromatographic separation over activated charcoal at $-80^{\circ} \mathrm{C}$ (Bruns, 1976), or the aging process based on a stand time of 30 days. Based on the search of literature relating to LS counting, a high temperature $\left(900^{\circ} \mathrm{C}\right)$ vacuum pull following the lithium carbide production stage (Barker, 1953) was originally considered adequate to remove radon originating in the sample (eg, Polach, Gower \& Fraser, 1972). Thus, the generated $\mathrm{C}_{2} \mathrm{H}_{2}$ and the synthesized $\mathrm{C}_{6} \mathrm{H}_{6}$ used for LS ${ }^{14} \mathrm{C}$ age determinations was considered radon-free. When, early in the 1970 s, some radon contamination of benzene was observed at the Australian National University (ANU), the stand-time method enabling radon to decay to insignificant levels or the mathematical method based on the observed decrease in count rate (Gupta \& Polach, 1985, p 109) were routinely applied.

The advent of high-resolution low-level multiparameter multichannel LS spectrometers (Kojola et al, 1984) enabled spectral identification of 
radioisotopes, and the qualitative determination of radon in the sample benzene. LS spectrometers, enabling simultaneous $\alpha$ - and $\beta$-particle energy and pulse shape resolution (Oikari et al, 1987), prompted Polach and Kaihola (1988) to propose that multilabeled samples (eg, ${ }^{14} \mathrm{C},{ }^{222} \mathrm{Rn}$ and its daughters) could be quantitatively resolved and, based on this, a precise ${ }^{14} \mathrm{C}$ activity correction factor determined.

On analyzing $>1000$ samples, using a high-resolution low-level LS spectrometer and an $\alpha / \beta$-particle pulse height and pulse shape LS spectrometer, we found that ${ }^{226} \mathrm{Ra}$ is not present and that ${ }^{222} \mathrm{Rn}$ is quantitatively removed, irrespective of source or concentration, during dynamic vacuum recovery of benzene at $-78^{\circ} \mathrm{C}$.

\section{EXPERIMENTAL}

\section{Equipment and Procedure}

For simultaneous $\alpha / \beta$-particle resolution, we used, at Beta Analytic, a Pharmacia-Wallac 1219 Spectra Master ${ }^{\mathrm{TM}}$ LS spectrometer enabling pulseheight and -shape analyses (Oikari et al, 1987). For high-sensitivity $\beta$-particle determinations, we used, at ANU, a low-level, high-resolution Pharmacia-Wallac 1220 Quantulus ${ }^{\mathrm{TM}}$ LS spectrometer enabling only pulse-height analyses but at very low backgrounds (Polach, 1987).

The sample preparation techniques of the three laboratories (including University of Miami, UM) are based on the benzene synthesis procedures established by Tamers, Stipp and Collier (1961) and Noakes, Kim and Stipp (1965). In revised form used at ANU (Polach \& Stipp, 1967), UM (Stipp, 1973) and Beta Analytic (Tamers, 1975).

Spectral resolution of $\alpha$-particle decaying ${ }^{222} \mathrm{Rn}$ in the range of 5-6 MeV from the ${ }^{14} \mathrm{C} \beta$-particle energy range at $0-155 \mathrm{keV}$ is complete. Only the $\beta$ particle-emitting decay daughters of ${ }^{222} \mathrm{Rn}$, namely ${ }^{214} \mathrm{Bi}$ and ${ }^{214} \mathrm{~Pb}$, contribute to count rates in the ${ }^{14} \mathrm{C}$ region of interest (Polach \& Kaihola, 1988). As both of the counters used enable simultaneous multiple 1024 channel spectra to be accumulated, the 'soft window' data analysis approach postulated by Polach et al (1983) was used.

Sample benzene synthesis at ANU was characterized by $900^{\circ} \mathrm{C}$ dynamic pumping to a high vacuum of the lithium carbide and recovery of synthesized benzene from the catalyst was at liquid nitrogen temperatures $\left(-180^{\circ} \mathrm{C}\right)$, first $20 \mathrm{~min}$ under static vacuum, followed by dynamic pumping for $40 \mathrm{~min}$ (Polach, Gower \& Fraser, 1972). Contamination of benzene samples with radon was frequently observed, casting doubts about the dependability of the $900^{\circ} \mathrm{C}$ lithium carbide after-heating as a radon removal step.

Sample benzene synthesis at Beta Analytic and UM employ the same after-heating procedures but benzene was recovered at dry ice-alcohol temperatures $\left(-78^{\circ} \mathrm{C}\right)$ under vacuum (Tamers, 1975 , p 678). Contamination with radon was never observed.

The present investigation uses organic samples 1) naturally contaminated by radon, 2) known to contain no radon as well as analytical reagent benzene (radioactive isotope-free), 3) labeled with ${ }^{14} \mathrm{C}$ and/or ${ }^{222} \mathrm{Rn}$ to trace the radon sources and determine the efficiency of the radon removal steps. 
Radon was generated by placing a sample of pitchblende, a uraniumrich mineral, into flasks containing both air and pure $\mathrm{CO}_{2}$, and allowed to stand for a month. Radon-rich air was then withdrawn by syringe and the benzene sample aerated with $5 \mathrm{ml}$ of the gaseous mix. Alternatively, the radon-contaminated $\mathrm{CO}_{2}$ was used for benzene synthesis, after adequate dilution.

The highest radon spike count rate tested was $200 \mathrm{cpm}$ in the radon window. This, given our $\sim 3.5 \mathrm{~g}$ carbon sample size, is $\sim 5$ times the activity of the modern ${ }^{14} \mathrm{C}$ reference standard and is twice as high as any natural radon contamination observed in the 23 years of dating experience at ANU.

\section{RESULTS AND DISCUSSION}

A typical benzene background spectrum obtained at Beta Analytic using a) liquid nitrogen benzene recovery, thin line, showing clear radon and daughters peak between channels 600 and 900 and b) dry-ice recovery of the same sample, thick line, radon free, is shown in Figure 1. We

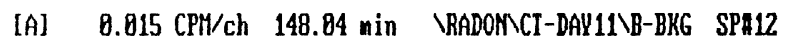

[B] $0.015 \mathrm{CPM} / \mathrm{ch} 148.83$ min IRADONCT-DAY12NMI-BKG SPH12

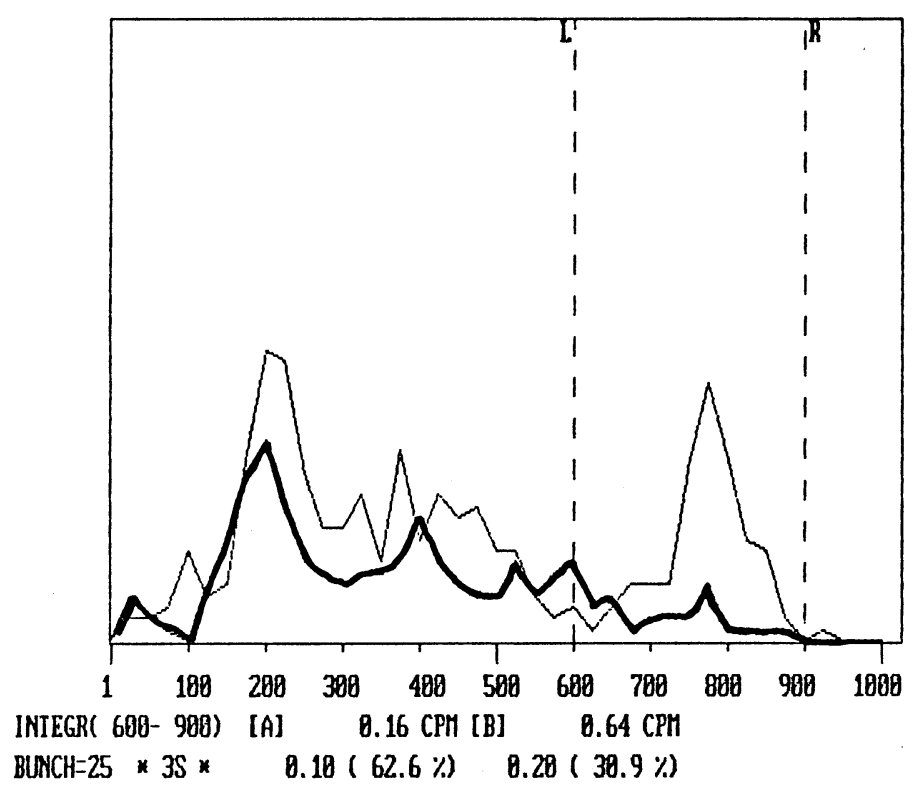

Fig 1. The thick curve was obtained from aerated reagent-grade dead benzene solutions loaded and counted in the laboratory of a one-story building with many windows and frequent air 'turn-over'. The thin curve is from similar solutions loaded and counted in a basement laboratory with no windows and poor air 'turnover'. The characteristic ${ }^{222} \mathrm{Rn}$ peak is apparent in both much higher in the poorly 'air-cycled' lab. Since all the solutions were prepared from the same reagent bottle, ${ }^{222} \mathrm{Rn}$ was introduced during the loading stage and reflected a higher content within the basement lab. 
analyzed 326 samples, 112 backgrounds and 18 reference standards at Beta Analytic. None were contaminated by detectable radon if the benzene was recovered from the catalyst at $-78^{\circ} \mathrm{C}$ while continuously pumping (dynamic vacuum).

Analysis of records held at ANU show that, prior to adoption of the Stipp/Tamers benzene recovery technique, 1965-April 1987, 1 in 10 samples was partially contaminated with radon. Severe contamination seldom occurred, as there was a built-in delay time between benzene synthesis and counting. Since April 1987, $>600$ benzene samples (unknowns, backgrounds and standards) were recovered under dynamic vacuum at $-78^{\circ} \mathrm{C}$. None showed traces of radon, unless the benzene was artificially contaminated after recovery.

Tests with radon-labeled $\mathrm{CO}_{2}$ showed that benzene recovered at liquid nitrogen temperatures was contaminated with $200 \mathrm{cpm}$ in the radon window (the modern reference standard normal count rate is $40 \mathrm{cpm}$ in the ${ }^{14} \mathrm{C}$ window and is background in the $\mathrm{Rn}$ window). Recovery of the same sample at $-78^{\circ} \mathrm{C}$ and dynamic pumping showed no measurable traces of radon at very low backgrounds $(0.2 \mathrm{cpm})$. We concluded that removal of radon at tested concentration (which in the experience of the ANU laboratory exceeded that normally found in any of their samples) was quantitative.

Sources of radon contamination other than the sample were identified as follows:

1) $\mathrm{O}_{2}$ used for sample combustion and $\mathrm{CO}_{2}$ used for sample dilution contained measurable traces of radon. These gases were stored in steel cylinders, some of which must have incorporated traces of uranium during their manufacture.

2) The chromium and vanadium catalyst used for benzene synthesis were tested by adsorbing first an analytical reagent-grade benzene (no radioactive isotopes) and then desorbing it, 24, 36 and 72 hours later, while trapping at liquid nitrogen temperatures. Traces of radon were identified and showed increasing levels with time.

3) Sample benzene recovered at $-78^{\circ} \mathrm{C}$ and dynamic pumping (thus containing no radon) was aerated in radon-free air as well as air naturally contaminated with radon. The benzene, exposed to only $20 \mathrm{ml}$ of the contaminated air, adsorbed from that small air mass measurable amounts of radon. (The natural radon count in the unventilated concrete room corresponded to $2.3 \mathrm{pCi} / \mathrm{L}$, which is not abnormal.)

\section{CONCLUSIONS}

LS spectrometry is a powerful tool enabling positive identification of radon in the benzene synthesized from the samples submitted for ${ }^{14} \mathrm{C}$ dating. Samples may be contaminated, while stored in the archives of nature, by ${ }^{226} \mathrm{Ra}$, hence ${ }^{222} \mathrm{Rn}$, or by radon in the laboratory atmosphere and reagents. Radon in concentrations corresponding to $200 \mathrm{cpm}$ (in our case $500 \mathrm{pM}$ ) originating in the sample and chemical reagents, such as gases, and catalyst will be quantitatively removed during benzene recovery, under dynamic pumping, at dry ice-alcohol or -acetone slush temperatures $(\sim 78 \mathrm{C})$. No 
measurable trace of residual radon could be detected in the sample benzene using very low background $(0.2 \mathrm{cpm})$ LS counters or simultaneous $\alpha / \beta$ particle pulse-shape analysis. We conclude that radon-free benzene samples can be prepared for LS counting without applying "radon" corrections. However, the benzene may be recontaminated during its necessary air equilibration by environmental radon accumulated in the basement of buildings or emanating from concrete/clay brick structures. A source of clean, radon-free air needs to be used to aerate the samples. In the absence of LS spectrometry, ie, using fixed-window LS counting, monitoring countrates in a "radon counting window" is a prerequisite to ${ }^{14} \mathrm{C}$ dating quality control for very low-level background counters. Such monitoring has been the feature of the ANU and Beta Laboratories since their establishment.

\section{REFERENCES}

Andrews, J N and Lee, D J, 1979, Inert gases in groundwater from Bunter sandstone of England as indicators of age and palaeoclimatic trends: Jour Hydrology, v 41, p 233-235.

Barker, H, 1953, Radiocarbon dating: large scale preparation of acetylene from organic material: Nature, v 172 , p 631-632.

Bruns, M, (ms) 1979, Gas Chromatographie mit Radon-222: PhD dissert, Inst Umweltphysik, Heidelberg.

Freundlich, J C, 1972, Natural radon as a source of low level laboratory contamination, in Rafter, T A and Grant-Taylor, T, eds, Internatl ${ }^{14} \mathrm{C}$ dating conf, 8th, Proc: Wellington, New Zealand, Royal Soc New Zealand, p 537-546.

Gupta, SK and Polach, H A, 1985, Radiocarbon dating practices at ANU: Canberra, Radiocarbon Dating Research, $176 \mathrm{p}$.

Kojola, H, Polach, H, Nurmi, J, Oikari, T and Soini, E, 1984, High resolution low-level liquid scintillation beta-spectrometer: Internatl Jour Applied Radiation Isotopes, v 35, p 949 952.

Noakes, J E, Kim, S and Stipp, J J, 1965, Chemical and counting advances in liquid scintillation age dating, in Chatters, $\mathrm{R} M$ and Olson, $\mathrm{E} A$, eds, Internatl conf on ${ }^{14} \mathrm{C}$ and tritium dating, 6th, Proc: Clearinghouse for Fed Sci Tech Inf, NBS, Washington, DC, USAEC-650-652, p 68-92.

Oikari, T, Kojola, H, Nurmi, J and Kaihola, L, 1987, Simultaneous counting of low alpha- and beta-particle activities with liquid-scintillation spectrometry pulse-shape analysis: Internatl Jour Applied Radiation Isotopes, v 38, no. 10, p 875-878.

Polach, $\mathrm{H} \mathrm{A}, 1987$, Evaluation and status of liquid scintillation counting for radiocarbon dating: Radiocarbon, v 29, no. 1, p 1-11.

Polach, H, Gower, J and Fraser, I, 1972, Synthesis of high purity benzene for radiocarbon dating by liquid scintillation method, in Rafter, A T and Grant-Taylor, T, eds, Internatl ${ }^{14} \mathrm{C}$ dating conf, 8th, Proc: Wellington, New Zealand, Royal Soc New Zealand, Proc: $\mathrm{p}$ $145-157$.

Polach, $\mathrm{H}$ and Kaihola, L, 1988, Determination of radon by liquid scintilation $\alpha / \beta$ particle spectrometry: towards the resolution of $a^{14} \mathrm{C}$ problem: Radiocarbon, $v 30$, no. 1, p 19-24.

Polach, H A, Robertson, S, Butterfield, D, Gower, J and Soini, E, 1983, Windowless approach to scintillation counting: low-level ${ }^{14} \mathrm{C}$ as an example, in McQuarrie, SS, Ediss, $\mathrm{C}$ and Wiebe, LI, eds, Advances in scintillation counting: Alberta, Univ Alberta Press, $\mathrm{p}$ 494-507.

Polach, H A and Stipp, J J, 1967, Improved synthesis techniques for methane and benzene radiocarbon dating: Internatl Jour Applied Radiation Isotopes, v 18, p 359-364.

Stipp, J J, 1973, Research/teaching course laboratory manual: Univ Miami.

Tamers, M A, 1975, Chemical yield optimization of the benzene synthesis for radiocarbon dating: Internatl Jour Applied Radiation Isotopes, v 26, p 676-682.

Tamers, M A, Stipp, J J and Collier, J, 1961, High sensitivity detection of naturally occurring radiocarbon, I-Chemistry of the counting sample: Geochim et Cosmochim Acta, v 24, p 266-276.

Vries, $\mathrm{H}$ de, 1957, The removal of radon from $\mathrm{CO}_{2}$ for use in ${ }^{14} \mathrm{C}$ age measurements: Applied Sci Research, sec B, v 6, p 461-470. 